\title{
A Piezoelectric Microvalve for Compact High-Frequency, High-Differential Pressure Hydraulic Micropumping Systems
}

\author{
David C. Roberts, Hanqing Li, J. Lodewyk Steyn, Onnik Yaglioglu, S. Mark Spearing, Member, ASME, \\ Martin A. Schmidt, Senior Member, IEEE, and Nesbitt W. Hagood
}

\begin{abstract}
A piezoelectrically driven hydraulic amplification microvalve for use in compact high-performance hydraulic pumping systems was designed, fabricated, and experimentally characterized. High-frequency, high-force actuation capabilities were enabled through the incorporation of bulk piezoelectric material elements beneath a micromachined annular tethered-piston structure. Large valve stroke at the microscale was achieved with an hydraulic amplification mechanism that amplified $(40 \times-50 \times)$ the limited stroke of the piezoelectric material into a significantly larger motion of a micromachined valve membrane with attached valve cap. These design features enabled the valve to meet simultaneously a set of high frequency $(\geq 1 \mathrm{kHz})$, high pressure $(\geq 300 \mathrm{kPa})$, and large stroke $(20-30 \mu \mathrm{m})$ requirements not previously satisfied by other hydraulic flow regulation microvalves. This paper details the design, modeling, fabrication, assembly, and experimental characterization of this valve device. Fabrication challenges, such as deep-reactive ion etching of the piston and valve membrane structures, wafer-level silicon-to-silicon fusion bonding, wafer-level and die-level silicon-to-glass anodic bonding, preparation and integration of piezoelectric material elements within the micromachined tethered piston structure, and filling of degassed fluid within the hydraulic amplification chamber are detailed.

[829]
\end{abstract}

Index Terms-Hydraulic amplification, MEMS, micropump, microvalve, piezoelectric.

\section{INTRODUCTION}

$\mathbf{T}$ HE development of a fluidic microvalve, capable of high-frequency control of high-differential pressure liquid fluid flows, is a key task in the realization of compact high performance micropumping technology. Currently, many research efforts around the world are underway to develop compact liquid micropumping systems, the term "micro" referring to devices which are created with fabrication procedures capable of $\mu m$-size tolerances and which produce overall micropump dimensions on the order of a few millimeters to a few centimeters. However, the vast majority of these systems are designed for low pressure and low flow rate applications (i.e., drug dispensing and microdosing) [1]-[8]. The higher performing

Manuscript received March 18, 2002; revised July 12, 2002. This research was assisted by the staff at the Microsystems Technology Laboratory at MIT and supported by DARPA under Grant \#DAAG55-98-1-0361 and by ONR under Grant \#N00014-97-1-0880. Subject Editor H. Fujita.

D. C. Roberts and N. W. Hagood are with the Continuum Photonics, Inc., Billerica, MA 01821 USA (e-mail: droberts@continuumphotonics.com).

H. Li, J. L. Steyn, O. Yaglioglu, S. M. Spearing, and M. A. Schmidt are with the Massachusetts Institute of Technology (MIT), Cambridge, MA 02139 USA.

Digital Object Identifier 10.1109/JMEMS.2002.807471 of these systems are capable of pumping liquids with flow rates on the order of 1000-3000 $\mu \mathrm{L} / \mathrm{min}(0.017-0.050 \mathrm{~mL} / \mathrm{s})$ against differential pressures of no more than $10-50 \mathrm{kPa}$.

In an effort to develop higher differential pressure and higher flow rate micropumping systems for both actuation and power generation applications, a novel class of micro-hydraulic transducer (MHT) devices has been introduced [9]-[13]. These devices, which integrate bulk piezoelectric materials within stiff micromachined structures to form a fluid pumping chamber and two active valves, are designed to enable high frequency pumping of fluid $(1-10 \mathrm{kHz})$ against pressure differentials on the order of $\sim 0.4-1 \mathrm{MPa}$, creating flow rates near or in excess of $0.5 \mathrm{~mL} / \mathrm{s}$. The performance of these MHT systems is directly governed by the pressurization, stroke, and frequency capabilities of the active valves employed. The development of a microvalve for use within these MHT systems is the subject of this paper.

Although a significant amount of literature is available describing the development of active valve devices and technology, few if any have been designed for high frequency control of high differential pressure liquid fluid flows. Microvalve designs using thermopneumatic actuation [14], [15], thermal bimetallic actuation [16], SMA actuation [17], electrostatic actuation [18], [19], electromagnetic actuation [20], [21], piezoelectric bender-type actuation (both thin-film and thick film) [22], [23], and piezoelectric stack-type actuation [24]-[26] have been presented. All of these microvalves share a common operational geometry in that a valve cap is affixed to a diaphragm or membrane structure which carries the cap through a predetermined stroke. Based on the reported capabilities, none of these valves is capable of simultaneously satisfying the set of high frequency, high differential pressure, and large stroke requirements needed within full MHT liquid micropumping systems.

The thermal actuation designs (based on thermopneumatic, thermal bimetallic, and shape memory alloy principles) potentially can achieve large stroke and reasonable actuation force. However, these devices exhibit excessive power consumption and poor response times on the order of seconds. High-frequency actuation in the $\mathrm{kHz}$ range is unachievable. The electrostatic devices are limited in their deflection and pressure generation capabilities, since the electrostatic force generated between two parallel plates scales inversely with their spacing and since electrical breakdown across the gap must be avoided. The electromagnetic concepts are impeded by the overall size of external solenoid and housing structures 
needed to actuate the valve structure. Piezoelectric thin-film and thick-film bender-type designs are limited in their ability to generate both high force and large deflection output. The work in [24]-[26] aimed at solving this limited valve stroke problem through the use of a stack-type piezoelectric actuator material attached directly to the valve membrane. In order to achieve a reasonable stroke of $8 \mu \mathrm{m}$, however, the piezoelectric stack material was required to be quite long $(\sim 9 \mathrm{~mm})$, and the valve membrane structure was designed to be relatively compliant to compensate for the tolerance mismatch between the stack and the surrounding structure. These characteristics resulted in limited differential pressure $(<50 \mathrm{kPa})$ and limited frequency $(<50 \mathrm{~Hz})$ capabilities for the valve device.

A promising concept for achieving high frequency operation $(\geq 1 \mathrm{kHz})$ in conjunction with large differential pressure $(\geq 300 \mathrm{kPa})$ and large valve stroke $(20-30 \mu \mathrm{m})$ capabilities involves the use of miniature-sized bulk piezoelectric elements (for example $1 \mathrm{~mm}$ in thickness - almost an order of magnitude smaller in length than those in [24]-[26]), actuating a stiff micromachined piston-type structure, with an integrated area-ratio hydraulic amplification mechanism for amplifying the limited deflection of the piezoelectric material into a significantly larger valve cap stroke. This concept for microscale systems has been introduced in [12] and [13]. Numerous macroscale piezoelectric hydraulic amplification mechanisms have been presented in the literature. In an application for active vibration control, a piezoelectric actuator uses the volume change of a piezoelectric ring to create a large deflection of a smaller area contact surface [27]. In an application for vibration control of a rotary dynamic system, the deflection of a stack-type piezoelectric actuator is coupled through an hydraulic line to a smaller size piston, which helps to control the motion of a rotating shaft [28]. These and other [29] piezoelectric hydraulic amplification mechanisms are novel in design, yet do not face the difficult fabrication, assembly, and tolerancing challenges inherent in the development of microscale systems.

This paper details the development of a compact piezoelectric hydraulic amplification microvalve to enable the realization of high frequency, high differential pressure micropumping systems. The paper is organized as follows. Section II describes the microvalve geometry and its principle of operation. Section III presents modeling tools and dynamic simulations that were developed to design the valve structure. Section IV outlines the fabrication and assembly procedures developed to create the active valve device. Section V details the results of two subcomponent studies carried out to validate the concept of the active valve. Section VI outlines the final active valve design geometry. Section VII presents an overview of the measurement set-up and experimental test plan to evaluate the valve performance. Section VIII discusses the experimental results and provides model-experiment correlation for the quasistatic and dynamic performance of the active valve device. Last, Section IX presents conclusions for this research work.

\section{PRINCIPLE OF OPERATION}

The microvalve geometry is shown in Fig. 1. The active valve consists of three primary components: a piezoelectric drive ele-

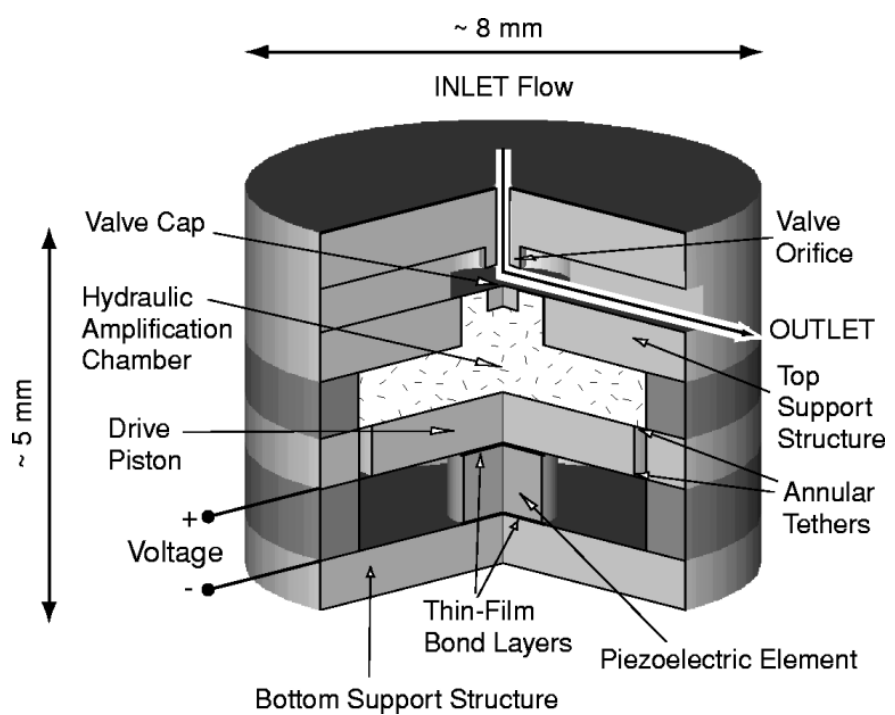

Fig. 1. A schematic of the piezoelectrically driven hydraulic amplification microvalve. The primary structural components are designated with arrows. External hydraulic system pressure loading is applied on the top surface of the valve cap and membrane.

ment, an enclosed hydraulic amplification chamber (HAC), and a membrane with attached valve cap. The drive element incorporates a circular piston structure supported from beneath by one or more small bulk piezoelectric cylinders and is suspended circumferentially from a surrounding support structure by thin annular micromachined tethers. This novel compact "piston-type" design enables high frequency actuation against a large external pressurization due to the high stiffness of the piston structure and integration of miniature bulk piezoelectric elements beneath the piston using a thin-film bond layer.

The lateral dimensions of the tethers are designed to make the tethers compliant enough to allow for rigid piston motion up and down, yet stiff enough to resist bowing under pressurization caused by the hydraulic fluid above the tether during actuation. The tethers provide a seal between the hydraulic fluid above the piston and the piezoelectric chamber below the piston, and also provide a path for electrical contact to the top surface of the piezoelectric cylinders. The fluid chamber resides between the top surface of the drive element piston and the bottom surface of a thin, smaller diameter silicon micromachined valve cap membrane. In response to applied piezoelectric voltage, the piezoelectric material strains. The resulting deflection of the drive element piston generates a pressure within the hydraulic amplification chamber which in turn deflects the valve cap and membrane against a fluid orifice, thereby regulating fluid flow through the external hydraulic system. The pressure loadings on the valve cap and membrane during device operation depend on the external microfluidic system application. The piezoelectric material capabilities, the ratio of the piston diameter to the valve membrane diameter, the compliances of the fluid and structural elements in the chamber, the severity to which the valve cap membrane experiences nonlinear behavior, and the nature of the external loading all contribute to the performance of this microvalve device. 


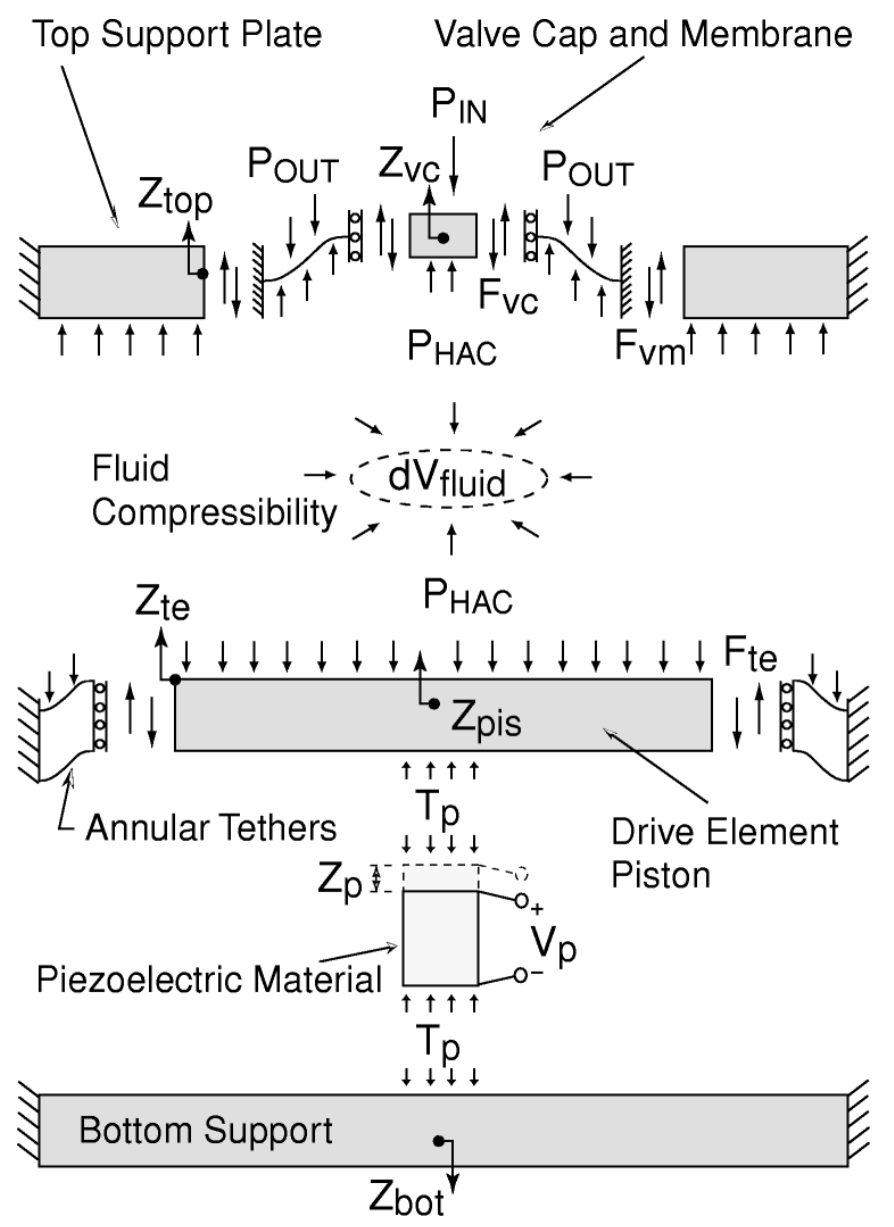

Fig. 2. Structural components included within active valve analytical model. All structures were modeled using linear theory, except for the valve cap and membrane structure, which required the development of nonlinear numerical modeling tools.

\section{MODELING AND Simulation}

Comprehensive quasistatic and dynamic analytical modeling tools were developed in an effort to design the valve structure based on operational requirements and subsequently to predict the valve behavior in response to applied piezoelectric material voltage and external pressure loading. As shown in Fig. 2, the piezoelectric material behavior, the bending of the drive element piston and deformation of the annular tethers, the hydraulic amplification chamber fluid compressibility, the structural compliance of the top support plate, the structural deformation of the bottom support plate, and the deformation of the valve cap and membrane structure were captured by these modeling tools (see Fig. 3).

The deformations of the plate structures were modeled using bending and shearing relations to determine the structural deflections and fluid swept volumes. Detailed discussions of these active valve modeling procedures are found in previous publications [12], [13]. Although the majority of structural deformations within the valve could be evaluated using linear plate theory, the modeling of the valve cap and membrane structure had to include in-plane tensile relations to properly capture the nonlinear large deflection behavior associated with valve cap deflections in excess of the membrane thickness. Associated

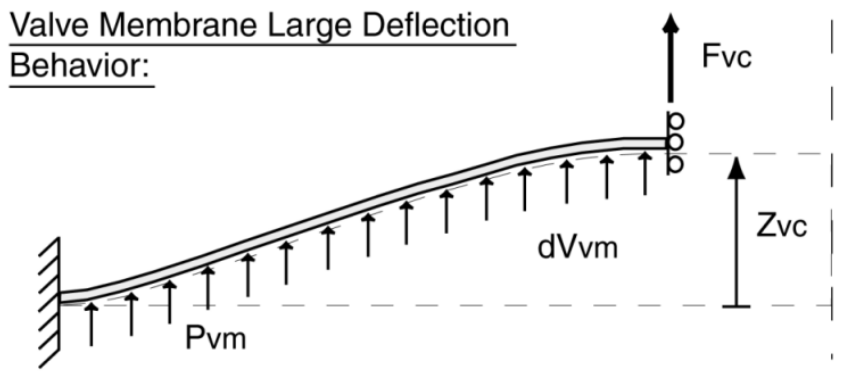

\section{Look-Up Tables:}

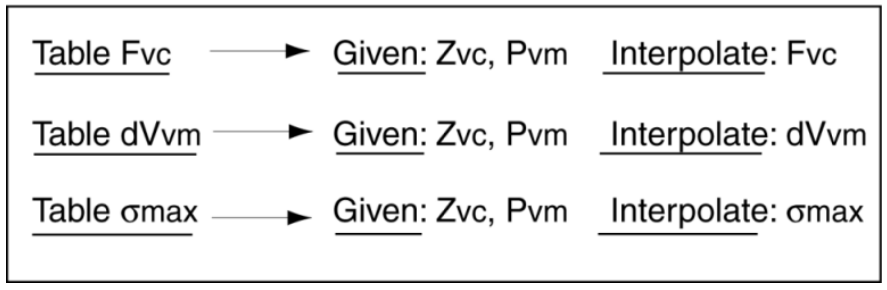

Fig. 3. Numerical modeling tools were used to generate look-up tables for the nonlinear large deflection behavior of the valve cap and membrane. Given a prescribed valve cap displacement $Z_{v c}$ and pressure loading across the membrane $P_{v m}$, a look-up table for each of $F_{v c}, d V_{v m}$, and $\sigma_{v m}$ was generated.

numerical modeling tools, detailed in [30], were incorporated into the overall active valve structural model for this purpose.

To capture the nonlinear effects of the valve membrane deformation at high frequency, and to include important dynamic effects, such as the drive element piston inertia and the valve cap inertia and damping, a Simulink simulation architecture was developed. The structural compliances within the active valve simulation were based upon the linear and nonlinear modeling tools discussed above. Look-up tables were implemented within the simulation to enable efficient calculation of the valve membrane deflections and stresses at every time step. Taking as inputs the valve cap displacement $Z_{v c}$ and the net pressure across the valve membrane $P_{v m}=P_{\mathrm{HAC}}-P_{\mathrm{OUT}}$, a lookup table was employed for each of the following output variables: the valve cap force on the membrane $F_{v c}$, the swept volume beneath the valve cap and membrane $d V_{v m}$, and the maximum radial stress in the membrane $\sigma_{v m}$.

Dynamic relations for the valve cap and drive element piston, schematically shown in Fig. 4, were also implemented to incorporate structural mass and damping. The dynamic behavior of the drive piston structure and the valve cap structure can be described by the following relations, respectively,

$$
\begin{aligned}
M_{\mathrm{pis}} \ddot{Z}_{t e}+C_{\mathrm{pis}} \dot{Z}_{t e} & =A_{p} T_{p}-A_{\mathrm{pis}} P_{H A C}+F_{t e} \\
M_{v c} \ddot{Z}_{v c}+C_{v c} \dot{Z}_{v c} & =A_{v c}\left(P_{\mathrm{HAC}}-P_{\mathrm{IN}}\right)+F_{v c}
\end{aligned}
$$

where $A_{\text {pis }}$ is the piston area, $M_{\text {pis }}$ is the piston mass, $A_{p}$ is the piezoelectric material area, $A_{v c}$ is the valve cap area, and $M_{v c}$ is the valve cap mass. The damping coefficient $C_{\text {pis }}$ is a lumped parameter that includes the effects of structural damping in the tethers and damping due to fluid-structural interaction within the hydraulic amplification chamber. The damping coefficient $C_{v c}$ is a lumped parameter that includes the effects of structural damping in the valve membrane and potential squeeze film 


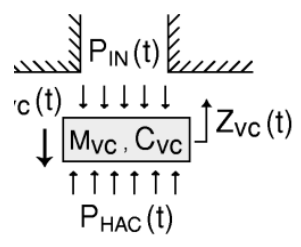

(a)

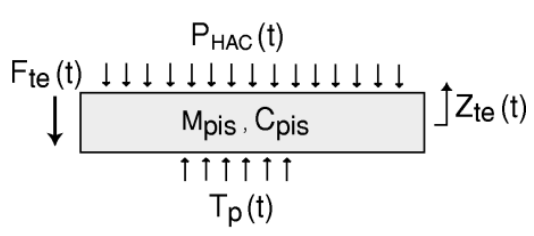

(b)
Fig. 4. Dynamic modeling of the valve cap and drive element piston structures: (a) valve cap mass, $M_{v c}$, and damping, $C_{v c}$; (b) piston mass, $M_{\text {pis }}$, and damping, $C_{\mathrm{pis}}$. Values for the damping coefficients were estimated, then verified through experimentation.

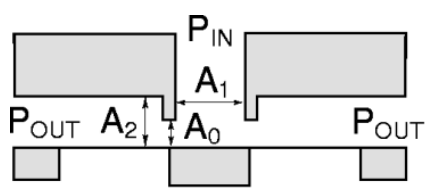

(a)

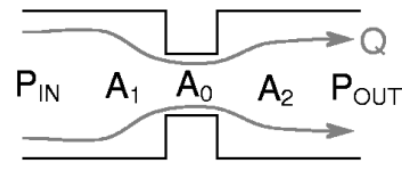

(b)
Fig. 5. Valve orifice representation: (a) valve cap geometry and fluid flow areas and (b) representation of flow through valve as a flow contraction followed by a flow expansion.

damping due to the valve cap motion as it closes against the fluid orifice.

Pressure-flow relations through the valve orifice were included in the overall valve simulation, with the orifice structure being represented by a flow contraction followed by a flow expansion. An integral analysis gives a relationship for the combined effect of this flow expansion and contraction. The loss coefficient $\varsigma_{\text {orifice }}$ is defined as the total pressure drop $\Delta P=P_{\mathrm{IN}}-P_{\mathrm{OUT}}$ over the dynamic pressure based on the orifice local mean velocity $\left(\bar{u}=Q / A_{o}\right)$,

$$
\text { Sorifice }=\frac{\Delta P}{\frac{1}{2} \rho \bar{u}^{2}}=\left[\frac{1}{2}\left(1-\frac{A_{0}}{A_{1}}\right)^{\frac{3}{4}}+\left(1-\frac{A_{0}}{A_{2}}\right)^{2}\right]
$$

where the upstream flow area is defined as $A_{1}$, the throat area is defined as $A_{0}$, and the downstream flow area is defined as $A_{2}$ (see Fig. 5).

This approximation holds only for Reynolds numbers in excess of 10000 (i.e., fully turbulent flow). In high-performance micropumping systems, Reynolds numbers fluctuating between 10 and 20000 are expected as the valve cap opens and closes [31]. For this reason, empirical correction factors were employed to obtain better estimates for the loss coefficients of the laminar and turbulent flow regimes within this range [31]. These higher order loss effects were represented with a Reynolds number dependent coefficient $C(R e)$ as a multiplier of $\varsigma_{\text {orifice, }}$ thereby altering the pressure-flow relation for the orifice,

$$
\Delta P=P_{\mathrm{IN}}-P_{\mathrm{OUT}}=\frac{1}{2} \rho C(R e) \varsigma_{\text {orifice }}\left(\frac{Q^{2}}{A_{0}^{2}}\right) .
$$

The structural and fluidic modeling tools presented in this section were combined to form a system-level Simulink simulation that was then used to design the active valve geometry to satisfy performance requirements and to provide model correlation for subsequent experimental results. The simulation architecture for the structural components of the active valve consisted of four major subsystems, as shown in Fig. 6: a matrix of linear coefficients describing the active valve structural behavior, including that of the piezoelectric material, a collection of nonlinear look-up tables that captures the large-deflection valve membrane deformation and stress behavior, a valve cap dynamics block, and a drive piston dynamics block.

\section{FABRICATION AND ASSEMBLY}

The fabrication process flow for the microvalve involved the micromachining and assembly of three silicon-on-insulator layers, two silicon layers, and four glass layers. A cross-section schematic of the microvalve device is shown in Fig. 7. The drive element tethered-piston structure was created through deep-reactive ion etching of Layers 4 and 5 separately, followed by wafer-level fusion bonding of the two wafers together to form a double-layer piston structure. During etching of the annular tethers in each of Layers 4 and 5, control of the fillet radii at the oxide etch-stop was critical, in order to minimize stress concentrations [32], [33]. Fig. 8 presents scanning-electron micrograph (SEM) images of a Layer 4 piston structure with well-controlled fillet radii, prior to bonding with Layer 5. The valve cap and membrane structure was also created using deep-reactive ion etching, with a similar requirement for good dimensional control of the fillet radii.

The middle glass layer (Layer 3) forms the drive element support structure and the top (Layer 9) and bottom (Layer 1) glass layers provide structural support. The bottom silicon layer (Layer 2) and drive piston silicon layers (Layers 4,5) provide a path for electrical contact to the piezoelectric cylinders. The top four silicon layers (Layers 4,5,7,8) and glass layer (Layer 6) house the hydraulic amplification chamber, valve cap and membrane structure, and fluid inlet and outlet channels. In order to provide a bottom structural stop for the valve cap as it moves away from the orifice, the Layer 6 glass layer was designed with a series of small through holes to connect the bottom portion of the hydraulic amplification chamber above the drive element piston to the top portion of the chamber directly beneath the valve cap and membrane. Although not shown in Fig. 7, a small fluid channel connecting the valve HAC chamber to an external pressure regulator was micromachined in Layer 7. This channel enabled control of a bias pressure $P_{\text {bias }}$ within the chamber during device testing, however, due to its flow impedance characteristics, effectively allowed high frequency $P_{\text {HAC }}$ pressure oscillations about the bias pressure during active valve operation. All glass wafers were machined ultrasonically. All silicon-silicon wafer interfaces were bonded with a wafer-level high-temperature $\left(\sim 1300^{\circ} \mathrm{C}\right)$ fusion bonding procedure, and all silicon-glass layer interfaces were bonded using a low temperature $\left(\sim 300{ }^{\circ} \mathrm{C}\right)$ anodic bonding process (either at the wafer-level or die-level depending on the process step) with an applied voltage of $1000 \mathrm{~V}$. Thin venting channels were etched in Layers 4 and 5 to prevent pressurization and potential plastic deformation or fracture of the piston tethers during the high temperature fusion bonding procedure. Attachment of the 


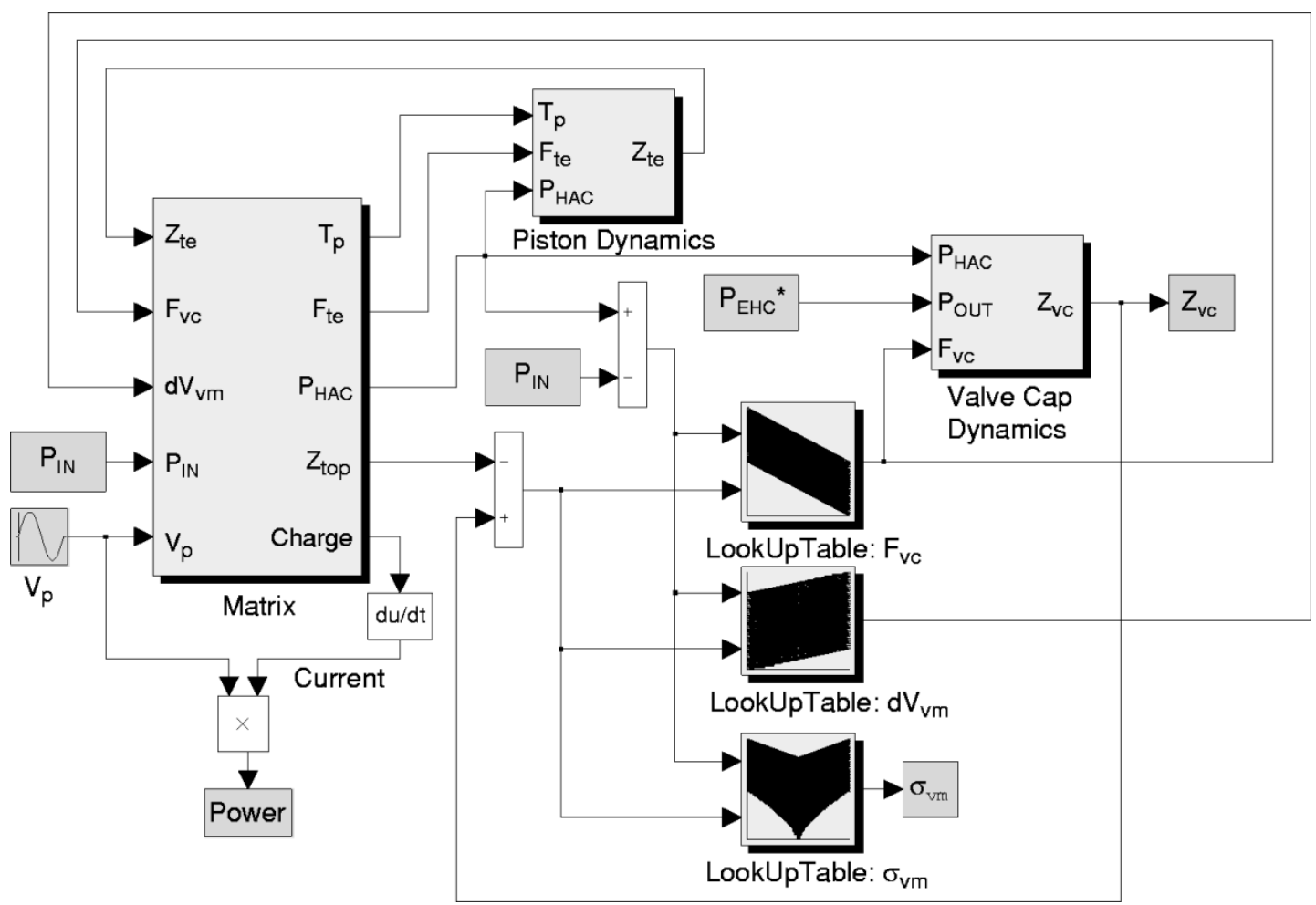

Fig. 6. Dynamic Simulink active valve system architecture, showing linear structural deformation matrix, valve cap and membrane nonlinear look-up tables, valve cap dynamics block, and drive element piston dynamics block. The fluid flow blocks are not shown in this figure.

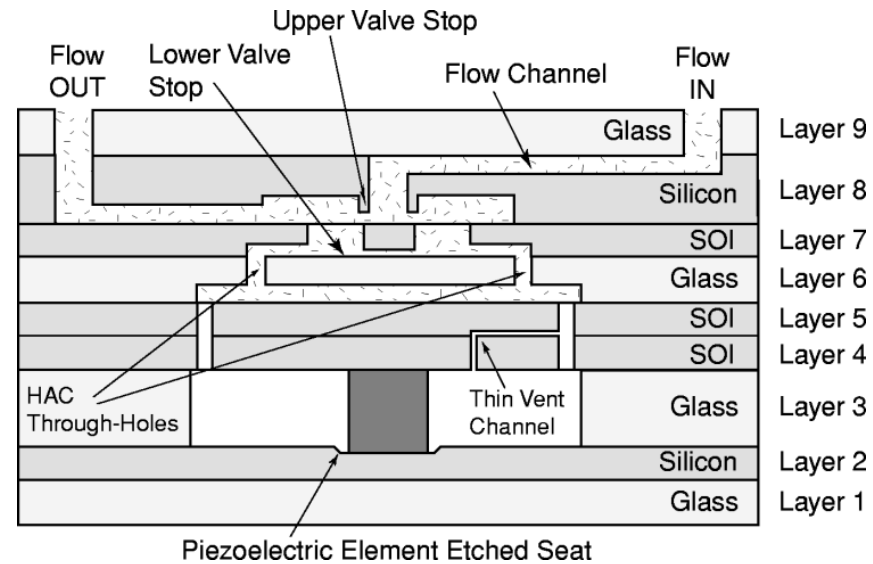

Fig. 7. Two-dimensional schematic of the multilayer silicon and glass microvalve structure. Five silicon layers, four glass layers, and one or more piezoelectric material cylinders are joined together to form the microvalve. Enclosed fluid within the hydraulic amplification chamber couples the drive element piston deflection to the valve cap motion.

top and bottom piezoelectric cylinder surfaces to the adjoining silicon was achieved with a low temperature $\left(\sim 300^{\circ} \mathrm{C}\right) \mathrm{AuSn}$ eutectic bond, as detailed in [11], [34].

A four layer film structure on the piezoelectric material and a three layer film structure on each of the adjoining silicon layers was deposited in preparation for bonding. The four layer structure on the piezoelectric material consisted of $50 \mathrm{~nm} \mathrm{Ti}, 250 \mathrm{~nm}$ $\mathrm{Pt}, 4000 \mathrm{~nm}$ AuSn, and $50 \mathrm{~nm} \mathrm{Au}$. The Ti served as an adhesion layer, the $\mathrm{Pt}$ as a diffusion barrier, and the final $\mathrm{Au}$ as a capping layer to prevent oxidation of Sn in the AuSn alloy. The AuSn layer, chosen to be thick enough $(4 \mu \mathrm{m})$ to compensate for the piezoelectric material surface roughness $(\sim 0.5 \mu \mathrm{m})$, was sputtered from an alloy target with $80 \mathrm{wt}$ \% Au and 20 wt. \% $\mathrm{Sn}$ composition. The three layer Ti-Pt-Au structure on each of the adjoining silicon pieces enabled the eutectic alloy to wet the silicon and was deposited on the die-level using e-beam evaporation procedures.

One of the critical issues during integration of the piezoelectric material elements was guaranteeing an upward deflection of the drive element piston large enough to ensure a preload on the eutectic alloy interface during bonding, yet small enough to ensure that stresses in the piston tethers during bonding and subsequent high-frequency operation were below critical levels. Typically, for the active valve structures developed in this research, limiting tether stresses near $1 \mathrm{GPa}$ [33] were reached for piston deflections approaching $10 \mu \mathrm{m}$. With a conservative safety factor taken into account, the devices were therefore toleranced such that a "piston push-up" of $\sim 2 \mu \mathrm{m}$ could be guaranteed. This tolerancing, shown in Fig. 9, was achieved by plasma etching shallow seats (typically $30-40 \mu \mathrm{m}$ in depth) beneath the piezoelectric element location in Layer 2.

Following the assembly of the active valve device, a procedure was carried out to pole the piezoelectric material within the drive element structure. This was done by heating the device to $70^{\circ} \mathrm{C}$ and applying an electric field across the piezoelectric element of $1000 \mathrm{~V} / \mathrm{mm}$. Once poled, the hydraulic amplification chamber of the device was filled and sealed with degassed silicone oil, as detailed in [35]. The active valve device was, at this point, ready for testing. A photograph of a completed nine-layer microfabricated valve is shown in Fig. 10, as part of a full chip-level MHT micropumping system. 


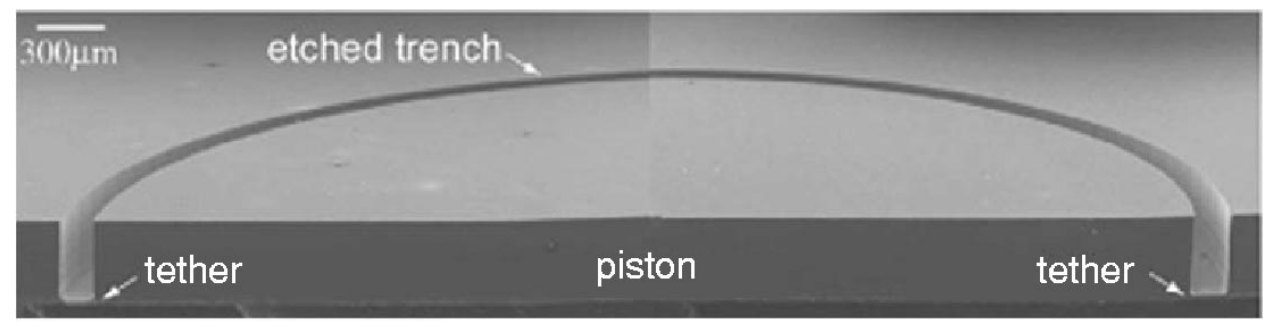

(a)

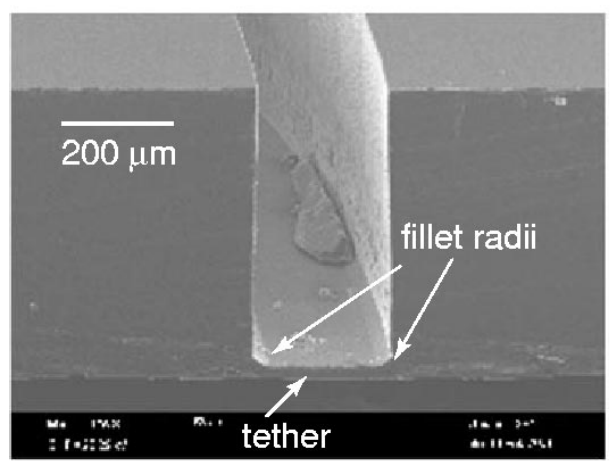

(b)

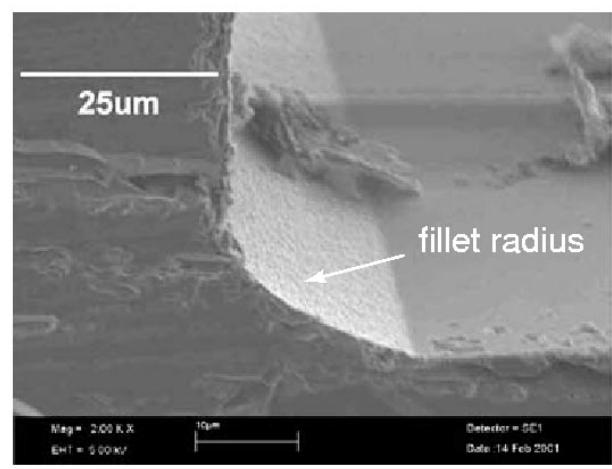

(c)

Fig. 8. SEM images of a Layer 4 etched drive element piston: (a) a cross section of the SOI piston structure, (b) a close-up of the etched trench, and (c) a further close-up of the fillet radius. In this structure, a 20-25 $\mu \mathrm{m}$ fillet radius was achieved. Debris in background was generated during die-saw procedures.

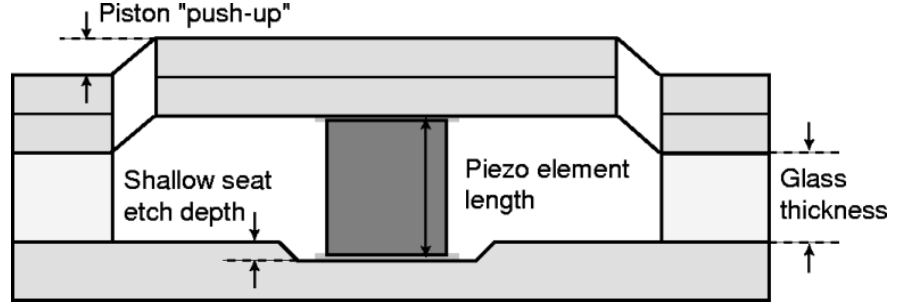

Fig. 9. Tolerancing of the piezoelectric element within the drive element structure was accomplished by etching shallow seats in the top surface of Layer 2. Precise control of the etch depth was necessary to achieve a controlled "push-up" of the drive element piston during bonding operations.

\section{VALVE SUBCOMPONENT VALIDATIONS}

The development program for this active valve device involved the validation of two primary subcomponent device platforms prior to assembly and characterization of the complete active valve device. These two subcomponent platforms were 1) the piezoelectric drive element structure, encompassing the challenge of integrating the miniature piezoelectric element(s) beneath the micromachined tethered piston structure and 2) the hydraulic amplification unit, as a means to prove the capability to fill the HAC chamber with degassed fluid and to achieve amplification of the piston motion into a significantly larger valve cap deflection.

\section{A. Drive Element Subcomponent Validation}

The purpose of this effort was to evaluate the fabrication and assembly process flow for integrating piezoelectric material elements within the micromachined drive element structure and to obtain quasistatic and high-frequency experimental data on the completed actuator structures. The previously published work [11] provides a comprehensive overview of this subcomponent study. In general, this study, through the assembly and testing of a series of drive element devices, proved the ability to integrate both single and multiple (three) piezoelectric material elements beneath double-layer micromachined tethered-piston structures, as shown in Fig. 11. The presence of three elements spread out beneath the piston enabled higher stiffness actuation capabilities by eliminating tilting and bending behavior of the piston structure. Additionally, this study verified that high-strain capability single-crystal (PZN-PT) piezoelectric material [36], in addition to standard polycrystalline PZT-5H material, could be successfully incorporated. Three-cylinder PZN-PT devices were experimentally characterized up to a frequency of $200 \mathrm{kHz}$ for drive voltages between $50 \mathrm{~V}$ and $1000 \mathrm{~V}$. Results showed that these microactuator structures exhibited negligible bending and tilting for quasistatic operation up to $15 \mathrm{kHz}$ and that first modal behavior did not occur until frequencies in excess of $80 \mathrm{kHz}$ [11].

\section{B. Hydraulic Amplification Validation}

The purpose of this effort was to validate the concept of hydraulic amplification between the piston and valve cap structures. HAC devices, consisting of Layers 4 through 9, were constructed to validate fluid filling and device operation without the effects of piezoelectric material integration beneath the piston structure. The previously presented work [35] provides a comprehensive overview of this subcomponent study. The assembled devices were successfully filled with degassed silicone oil (hexamethyldisiloxane, produced by Dow Corning under the trade name DC200 0.65 centistoke) and device amplification ratios up to $40 \times$ were measured. 


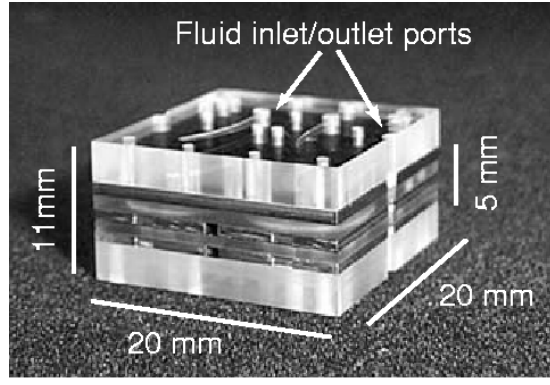

(a)

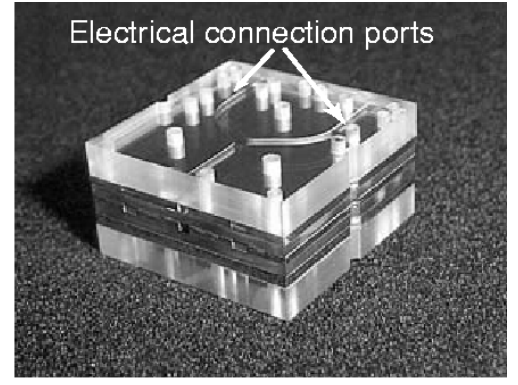

(b)

Fig. 10. Photograph of a nine-layer silicon and glass piezoelectrically driven hydraulic amplification microvalve, as part of a full MHT system. Dimensions of the valve structure within the full MHT chip are $8 \mathrm{~mm} \times 8 \mathrm{~mm} \times 5 \mathrm{~mm}$.
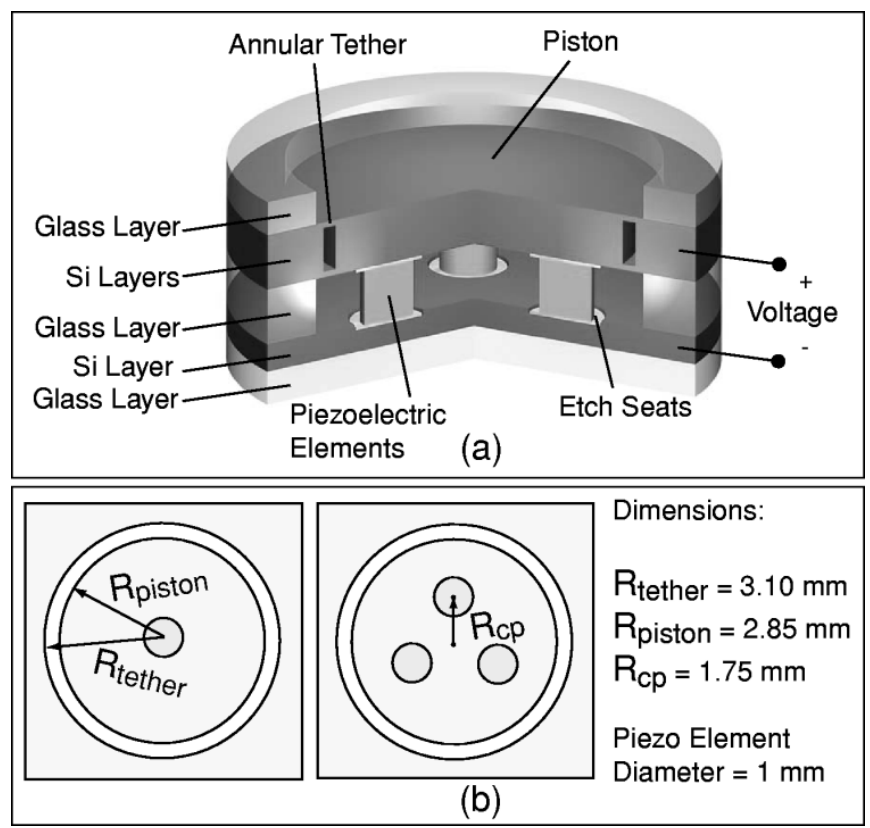

Fig. 11. Three-dimensional schematic of a piezoelectric drive element device. Three piezoelectric cylinders are sandwiched between a lower support silicon layer and an upper double silicon layer tethered-piston structure. Voltage is carried along the upper and lower silicon layers.

\section{Final Active Valve Dimensions}

The dimensions of the fabricated final active valve device are illustrated in Fig. 12. The device incorporated three PZN-PT piezoelectric square elements (each with cross-sectional area $1.06 \mathrm{~mm} \times 1.06 \mathrm{~mm}$ ) beneath a double-layer tethered piston structure. The top and bottom tethers of the piston were each $250 \mu \mathrm{m}$ in width and each had a thickness of $8 \mu \mathrm{m}$. A valve cap and membrane structure was positioned above the hydraulic amplification chamber, with a structural stop (formed by the glass Layer 6 within the HAC chamber) $\sim 16.5 \mu$ m below the equilibrium position of the valve cap. Glass Layer 6 contained a series of "HAC through-holes" to carry the fluid from the lower to upper portion of the HAC chamber. The valve cap had a diameter of $500 \mu \mathrm{m}$ and the valve membrane had an outer diameter of $1400 \mu \mathrm{m}$ and thickness of $6 \mu \mathrm{m}$. A valve orifice was located $\sim 16.5 \mu \mathrm{m}$ above the valve cap equilibrium position. The orifice had an inner diameter of $450 \mu \mathrm{m}$.

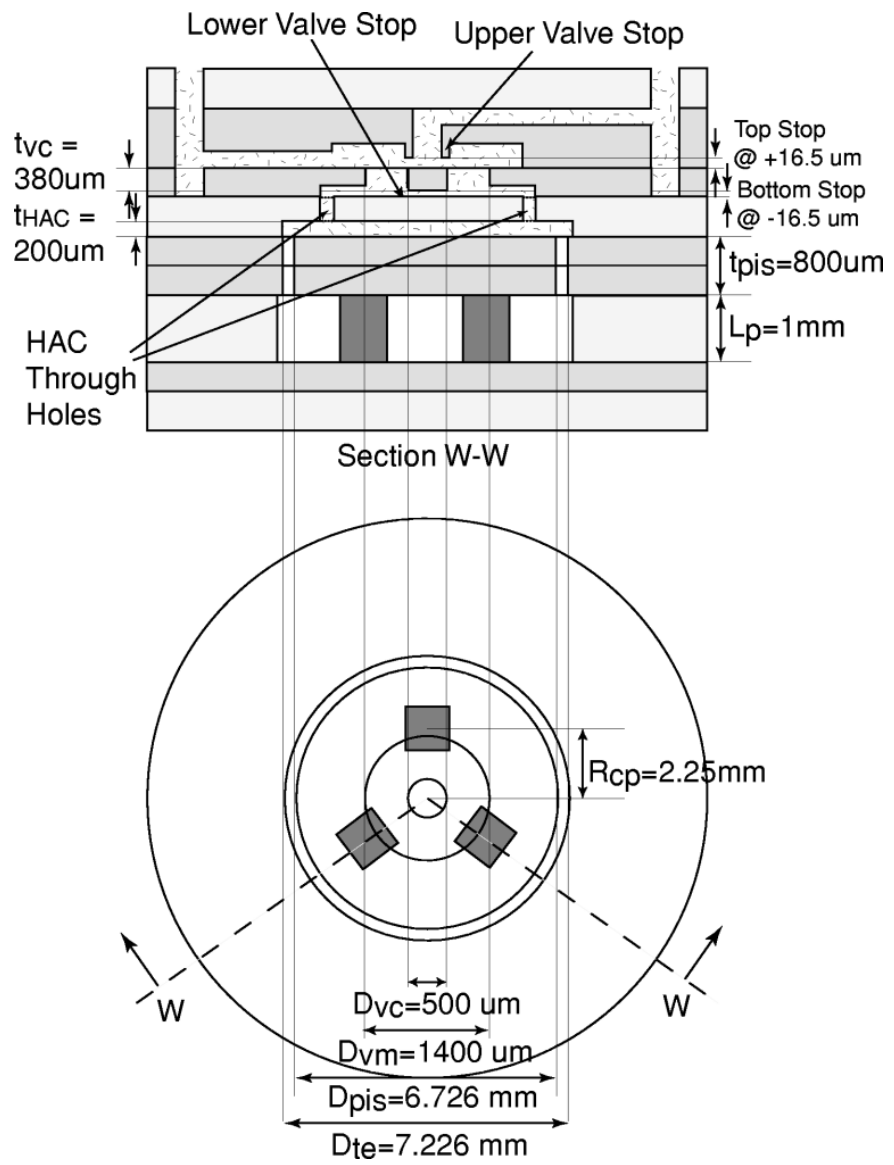

Fig. 12. Dimensions of the fabricated active valve devices. Three square PZN-PT elements were incorporated beneath a double-layer tethered piston. A valve cap and membrane structure interacts with the fluid orifice structure at $Z_{v c}=+16.5 \mu \mathrm{m}$ and with the glass Layer 6 structure within the HAC chamber at $Z_{v c}=-16.5 \mu \mathrm{m}$.

\section{EXPERIMENTAL Test Plan}

Testing of the active valve device was divided into two primary efforts. The first effort focused on characterizing the actuation capabilities of the valve structure without the effects of differential pressure and flowing fluid above the structure. In this effort, the dynamic behavior of the active valve device was evaluated and the range of driving frequency for which the valve behaved in a quasistatic manner was determined. Additionally, at the determined maximum quasistatic operational frequency, 
the structural amplification ratio of the valve device was characterized as a function of applied voltage to the piezoelectric drive element. Once the device was proven to be a successful actuator, the second effort focused on evaluating its flow regulation capabilities and limitations. In this effort, the flow regulation capability of the valve device at the maximum quasistatic operational frequency of the structure was evaluated as a function of increasing differential pressure across the valve orifice. In this manner, the valve performance limitations could be determined as the differential pressure was increased.

The aforementioned tests required the development of testing rigs and experimental procedures to measure accurately the drive element piston and valve cap structural vibrations within the multilayered device. A laser vibrometer system, with a micro-lens attachment, was used for these vibration measurements [37]. The active valve chip-level device was mounted in a test-jig which included fluid inlet and outlet ports to the chip, as well as through-holes for alignment of the vibrometer laser beam on the key structural components within the device. The accompanying fluids testing rig was comprised of fluid reservoirs, absolute and differential pressure sensors for measuring the inlet and outlet pressures into the device, and a calibrated real-time flow sensor for measuring flow rates through the valve. Additionally, a data-acquisition system was implemented to enable real-time drive signals to the device and measurements from the device and testing rig.

\section{RESULTS AND DISCUSSION}

\section{A. Device Actuation Capabilities}

To characterize the frequency-dependent behavior of the active valve device, a low-voltage $(0 \mathrm{~V} \pm 5 \mathrm{~V})$ sweep signal from $500 \mathrm{~Hz}$ to $100 \mathrm{kHz}$ was applied to the piezoelectric drive element structure. The valve cap and piston velocities were measured using the laser vibrometer system. The corresponding displacements were obtained through post-process integration of the velocity signals. Fig. 13 overlays the frequency response of the drive element piston with that of the valve cap, for the case in which oil is present above the valve structure but for which no differential pressure or flowing fluid occurred across the valve orifice. These tests were performed with $P_{\text {bias }}=500 \mathrm{kPa}$ to eliminate the possibility of cavitation within the HAC chamber. Additionally, the pressures above the valve cap and membrane were maintained at $P_{\mathrm{IN}}=P_{\mathrm{OUT}}=500 \mathrm{kPa}$.

The piston and valve responses both followed the same patterns across the frequency range. The valve first modal frequency was observed to occur at $\sim 5 \mathrm{kHz}$. The additional peaks in the response were most likely a result of fluid-structure interactions between the oil and the experimental test-jig flow tubes external to the device or between the oil and the flow channels internal to the device. The increase in piston displacement amplitude at frequencies below $1 \mathrm{kHz}$ was due to measurement limitations in the vibrometer system. Below $1 \mathrm{kHz}$, the measured velocities were of the same order as the noise floor, whereas at higher drive frequencies, the measured velocities were sufficiently above the noise floor to provide accurate measurements. The results indicate that the amplification ratio of the valve device was steady (between $40 \times-50 \times$ ) over the range of frequencies below resonance.
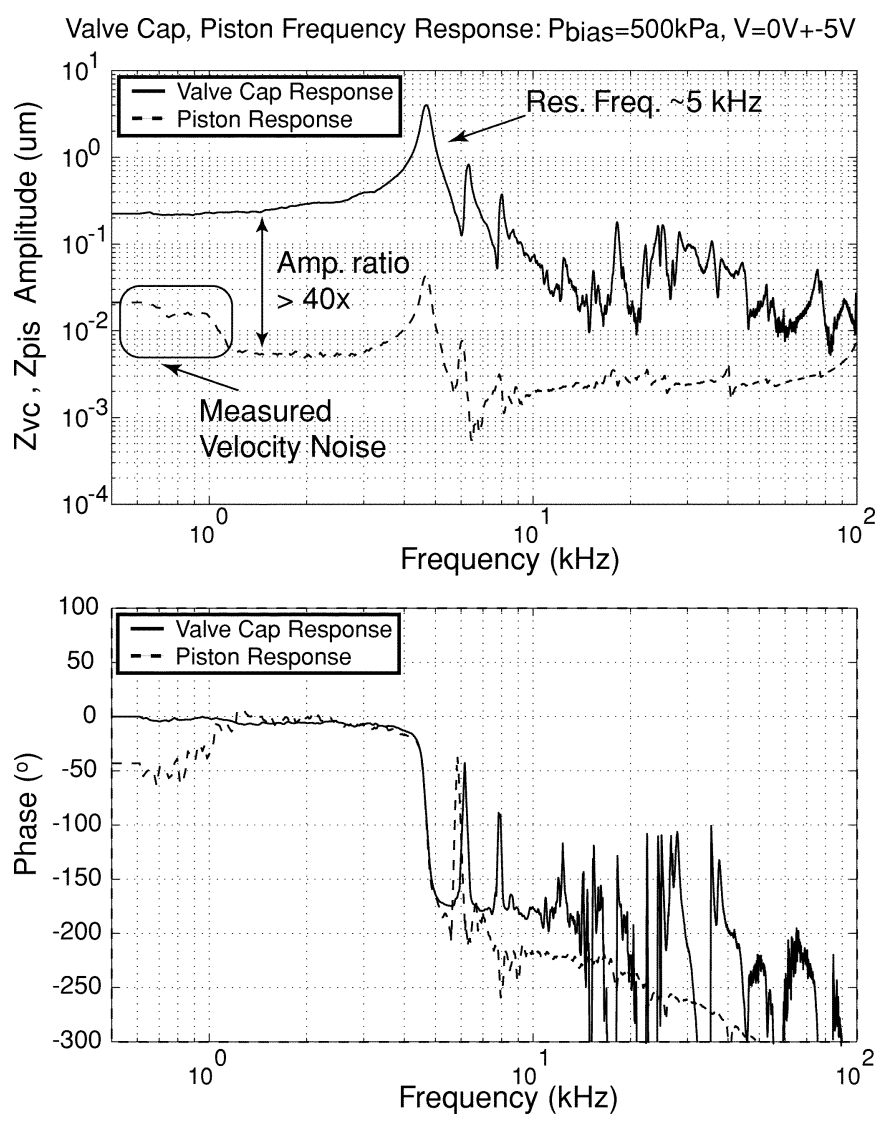

Fig. 13. Low-voltage $(0 \mathrm{~V} \pm 5 \mathrm{~V})$ piston and valve cap frequency responses from $500 \mathrm{~Hz}$ to $100 \mathrm{kHz}$, with oil present above the valve structure. The top figure plots the valve cap and piston amplitudes, while the bottom figure plots the corresponding phase. The bias pressure in these tests was maintained at $P_{\text {bias }}=500 \mathrm{kPa}$. An amplification ratio between $40 \times-50 \times$ is observed for frequencies below $5 \mathrm{kHz}$.

The previous frequency sweep experimental tests found the 1st modal frequency of the device to be $\sim 5 \mathrm{kHz}$. In order to evaluate the quasistatic performance of the structure under the larger drive voltage levels at which the valve was designed to operate, a frequency of operation of $1 \mathrm{kHz}$ was chosen. Fig. 14 plots the valve cap and piston displacement time histories, respectively, at this drive frequency over a range of applied voltages from $50 \mathrm{Vpp}$ to $800 \mathrm{Vpp}$. In Fig. 14(a), the dotted lines at $+16.5 \mu \mathrm{m}$ and $-16.5 \mu \mathrm{m}$ indicate the position of the upper and lower valve stops, respectively. For an applied voltage of $50 \mathrm{Vpp}$, the response of the valve cap was purely sinusoidal.

As the voltage was increased to $800 \mathrm{Vpp}$, the resulting valve cap displacement time history contained small amplitude higher frequency $(\sim 5 \mathrm{kHz})$ oscillations due to the nonlinear nature of the valve membrane structure. These oscillations became more pronounced as the voltage was increased. In Fig.14 (b), the drive element deflection time histories were somewhat rough in nature due to the noise level of the measurement system. As the deflections increased in amplitude, the effect of this noise floor diminished. It is important to note that for a voltage of $800 \mathrm{~V}$, the valve was not deflected sufficiently to close against the valve orifice. This was due to the fact that the actual piezoelectric material coefficient was only $\sim 75 \%$ of the expected value used for the original valve design (see further discussion in subsequent paragraphs). 
(a) Valve Cap Displacement: Freq. $=1 \mathrm{kHz}$, Pbias $=500 \mathrm{kPa}$

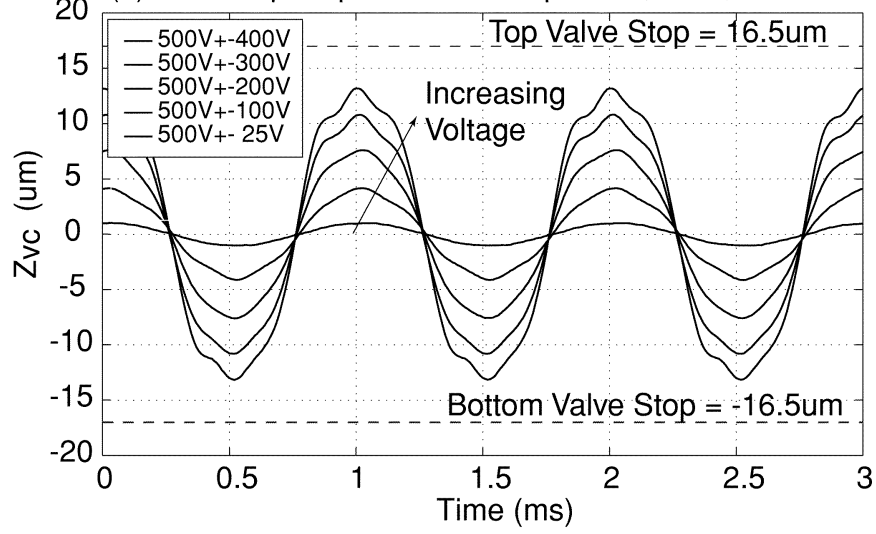

(b) Piston Displacement: Freq. $=1 \mathrm{kHz}$, Pbias $=500 \mathrm{kPa}$

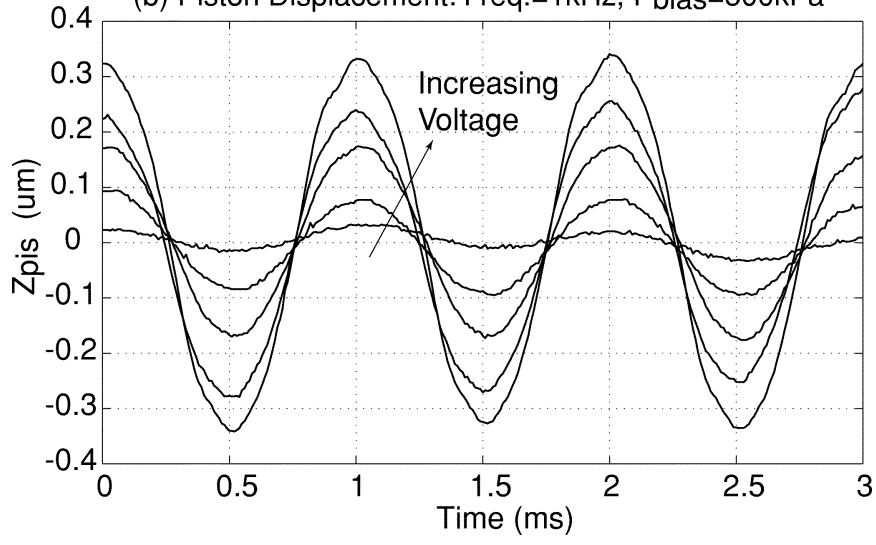

Fig. 14. Experimental valve cap and piston deflection time histories for a series of $1 \mathrm{kHz}$ sinusoidal drive voltage levels. As the voltage was increased, small amplitude $5 \mathrm{kHz}$ oscillations appeared in the deflection responses. Note that a voltage of $800 \mathrm{Vpp}$ was not sufficient to close valve cap against the valve orifice.

Fig. 15 takes these deflection time histories and plots the valve cap peak-peak displacement, piston peak-peak displacement, and corresponding device amplification ratio as a function of applied voltage to the piezoelectric drive element. The amplification ratio was observed to decrease from 50 to 40 as the voltage was increased, as illustrated in Fig. 15(c).

If the structural system was composed of elements operating only in their linear deformation regimes, this amplification ratio would remain constant over the voltage range. Due to the nonlinear stiffness of the valve membrane, however, constant incremental changes in voltage result in increased incremental changes in the chamber pressure and reduced incremental changes in valve cap deflection, as shown in Fig. 15(a). A similar result for the piston deflection is shown in Fig. 15(b). This curve, however, exhibits slightly more linearity than the valve cap deflection curve, due to the increased incremental changes in compressed fluid volume change and structural chamber deformation as the voltage is increased. In essence, as the voltage is increased, a smaller percentage of the piston swept volume is transformed into valve membrane swept volume, thereby resulting in a decreasing amplification ratio.

Fig. 15 also includes model predictions for this behavior. Shown on this plot are three curves generated from the active valve simulation tools discussed previously. The first curve is the predicted response based on the assumed piezo-
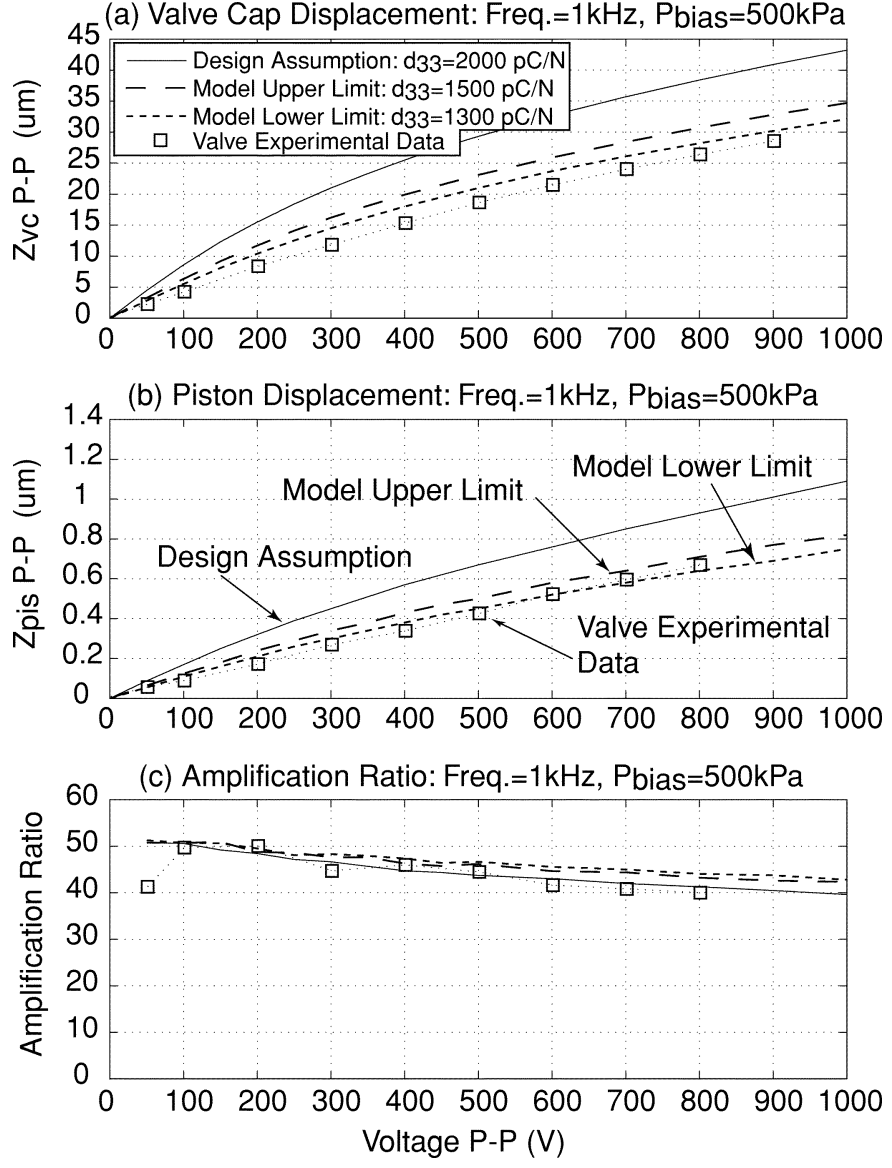

Fig. 15. Active valve quasistatic $1 \mathrm{kHz}$ model correlation for increasing applied voltage: (a) the valve cap deflection curve was $5-10 \%$ below the limiting bounds for $d_{33}=1300-1500 p C / N$, (b) the piston deflection curve fell within the limiting bounds for large voltage, and (c) the device amplification ratio (between $40 \times$ and $50 \times$ ) agreed very closely with the predicted limiting bounds.

electric material coefficient value of $d_{33}=2000 \mathrm{pC} / \mathrm{N}$ used in the original design of the active valve device. The second two model curves are based on limiting values of $d_{33}=1300-1500 \mathrm{pC} / \mathrm{N}$ determined by measuring a large number of individual piezoelectric elements and observing the range of piezoelectric coefficients. Active valve performance was therefore compared to these limiting model cases rather than the ideal case since the piezoelectric elements were determined to be inferior to original design assumptions. The model correlation indicates that the experimental valve cap deflection curve falls slightly short (at $800 \mathrm{Vpp}$ for example, the cap deflection was $26 \mu \mathrm{mP}-\mathrm{P}$ versus the predicted $31 \mu \mathrm{mP}-\mathrm{P})$ of the prediction limits for $d_{33}=1300-1500 p C / N$, while the experimental piston deflection curve falls within these limits for large enough applied voltage. Based on these results, it can be concluded that an additional compliance mechanism must exist within the HAC chamber, most likely due to a smaller than expected value of fluid bulk modulus. A fluid bulk modulus of $K_{f}=2 \mathrm{GPa}$ was assumed in the active valve models and simulations [37]. The corresponding device amplification ratio, as shown in Fig. 15(c) decreased slightly from $\sim 50 \times$ for a low voltage of $100 \mathrm{Vpp}$ to $\sim 40 \times$ for a high voltage of $800 \mathrm{Vpp}$, consistently within $5-10 \%$ of the limiting model predictions. 
TABLE I

Active Valve Actuation CaPabilities

\begin{tabular}{c|c|c}
\hline $\begin{array}{c}\text { Performance } \\
\text { Characteristics }\end{array}$ & $\begin{array}{c}\text { Experimental } \\
\text { Results }\end{array}$ & $\begin{array}{c}\text { Model } \\
\text { Predictions }\end{array}$ \\
\hline 1st Modal Frequency & $5 \mathrm{kHz}$ & $14 \mathrm{kHz}$ \\
\hline $\begin{array}{c}\text { Piston Deflection } \\
\text { @1kHz, 800Vpp) }\end{array}$ & $0.65 \mu m \mathrm{pp}$ & $0.72 \mu \mathrm{mpp}$ \\
\hline $\begin{array}{c}\text { Valve Cap Deflection } \\
\text { (@1kHz, 800Vpp) }\end{array}$ & $26 \mu m \mathrm{pp}$ & $31 \mu m \mathrm{pp}$ \\
\hline $\begin{array}{c}\text { Amplification Ratio } \\
\text { (1 } 1 \mathrm{kHz}, 800 \mathrm{Vpp})\end{array}$ & $40 \mathrm{x}$ & $43 \mathrm{x}$ \\
\hline
\end{tabular}

Table I summarizes the critical actuation capabilities of the active valve device in comparison to model predictions. As discussed previously, the valve 1st modal frequency occurred at $\sim 5 \mathrm{kHz}$. Finite-element models of this valve structure had predicted a 1 st modal frequency of $14 \mathrm{kHz}$, however, these models did not include the presence of oil above the valve cap and membrane structure. It was this added mass of the oil that reduced the 1 st modal frequency of the valve structure. Future modeling of the valve should more carefully include this added mass effect when predicting modal behavior. As for quasistatic operation at $1 \mathrm{kHz}$, as already discussed, the measured device valve cap deflection fell slightly short of predictions. However, the amplification ratio was in excellent agreement with model predictions. Overall, this encouraging device performance enabled further investigations into the valve's flow regulation capabilities.

\section{B. Device Flow Regulation Capabilities}

To evaluate the capability of the active valve device to regulate flow at $1 \mathrm{kHz}$, a series of tests was carried out for increasing imposed differential pressure across the valve orifice. Flow regulation tests were performed for differential pressures $P_{\mathrm{IN}}-P_{\text {OUT }}=24 \mathrm{kPa}, 95 \mathrm{kPa}, 145 \mathrm{kPa}, 200 \mathrm{kPa}, 260 \mathrm{kPa}$, and $340 \mathrm{kPa}$. A volatile silicone oil (hexamethyldisiloxane, produced by Dow Corning under the trade name DC200 0.65 centistoke) was used as the flow regulation fluid. By controlling $P_{\mathrm{HAC}}$ with respect to the magnitude of $P_{\mathrm{IN}}$ and $P_{\mathrm{OUT}}$ (using the high-frequency channel and corresponding bias pressure regulator set-up discussed previously), the valve cap was displaced statically upward to a deflection of $Z_{v c}=11 \mu \mathrm{m}$. A sinusoidal voltage of $500 \mathrm{Vpp}$ was then applied to the piezoelectric drive element at $1 \mathrm{kHz}$ to actuate the valve cap upward against the valve orifice and downward toward the original equilibrium position of the valve cap. In all test runs, it was desired to just barely close the valve cap against the orifice at its maximum displacement, and to maintain $Z_{v c}=0$ at its minimum displacement. In others words, it was desired to always ensure a valve opening stroke of $16.5 \mu \mathrm{m}$.

Fig. 16 plots the experimentally measured flow rates for each of the differential pressure test cases. An applied voltage of $500 \mathrm{Vpp}$ was held constant for all of the test cases, and the corresponding measured stroke of the valve cap during actuation is printed inside of each data bar. Fig. 16 also plots the experimental results versus the model expectations obtained using the active valve simulation tools detailed previously. Model predictions for chosen limiting valve strokes of $Z_{v c, P P}=13 \mu \mathrm{m}$ and $Z_{v c, P P}=17 \mu \mathrm{m}$ are shown. The model correlation indicates that the active valve regulates flow in excellent correlation

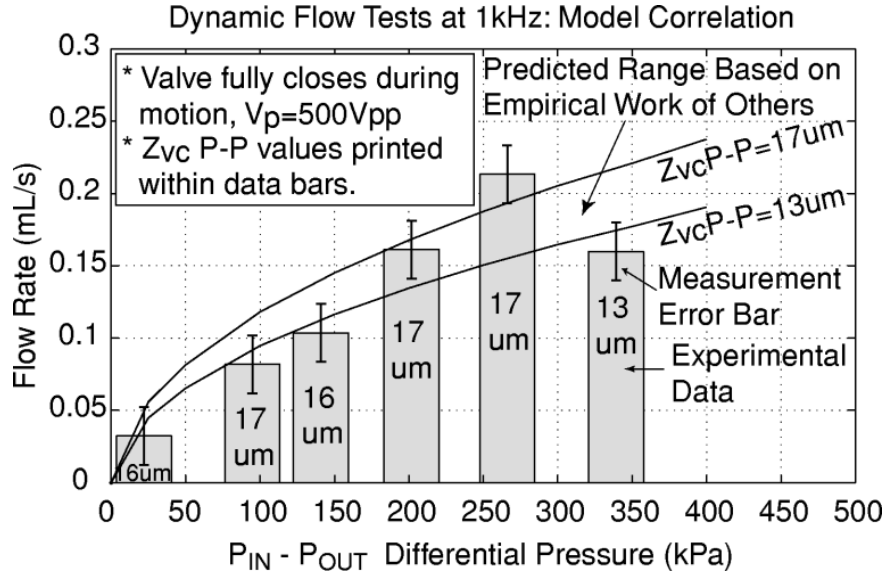

Fig. 16. Dynamic flow regulation model correlation at $1 \mathrm{kHz}$ for varying differential pressures. Correlation is good over range of differential pressures. Error bars on the data indicate the measurement error, which was estimated based on the flow sensor calibration error and the accuracy of the applied differential pressure.

with the model predictions. Since the flow loss coefficients used within the models discussed previously were based on a compilation of empirical Re data from other researchers, the line of predicted behavior in Fig. 16 is understood to be of only "limited accuracy," in other words, it is not based on exact theory.

Subsequent test runs at differential pressures in excess of $P_{\mathrm{IN}}-P_{\mathrm{OUT}}=340 \mathrm{kPa}$ resulted in unstable oscillatory motion of the valve cap structure, and eventually fracture of the valve membrane. The nature of the flow behavior (based on Reynolds number) was investigated for a variety of valve opening situations in subsequent studies. The results indicated that these self-excited valve cap oscillations were most probably a result of transitional flow (between laminar and turbulence) through the valve orifice structure, a regime which limited the valve operation to relatively low differential pressures of no more than $340 \mathrm{kPa}$. A comprehensive overview of these unstable oscillatory valve cap experiments is detailed in [37]. Future research work should focus on a better understanding of the flow regimes through these microscale orifice structures, especially as a function of different viscosity fluids, and on a redesign effort to develop a valve geometry which is less sensitive to the flow behavior passing through the orifice. Additionally, this redesign should include an effort to increase the 1st modal frequency of the device, to potentially enable operation at or above a frequency of $10 \mathrm{kHz}$. With these redesign efforts, a higher frequency, higher flow rate microvalve could be achieved.

\section{CONCLUSION}

A compact piezoelectrically-driven hydraulic amplification microvalve was successfully fabricated and tested for the first time. This concept of hydraulically amplifying the limited stroke of a miniature bulk piezoelectric material into a significantly larger motion of a valve cap structure enables the valve to simultaneously meet a set of high frequency $(\geq 1 \mathrm{kHz})$, high pressure $(\geq 300 \mathrm{kPa})$, and large stroke $(20-30 \mu \mathrm{m})$ requirements not previously satisfied by other hydraulic flow regulation microvalves. The active valve structural behavior and flow regulation capabilities were evaluated over a range 
of applied piezoelectric voltages, actuation frequencies, and differential pressures across the valve. For applied piezoelectric voltages up to $500 \mathrm{Vpp}$ at $1 \mathrm{kHz}$, the valve devices demonstrated amplification ratios of drive element deflection to valve cap deflection of $40 \times-50 \times$. These amplification ratios correlated within 5-10\% of the model expectations. Flow regulation experiments proved that a maximum average flow rate through the device of $0.21 \mathrm{~mL} / \mathrm{s}$ for a $1 \mathrm{kHz}$ sinusoidal drive voltage of $500 \mathrm{Vpp}$, with valve opening of $17 \mu \mathrm{m}$, against a differential pressure of $260 \mathrm{kPa}$ could be obtained. Tests revealed that fluid-structural interactions between the valve cap and membrane components and flow instabilities (due to transition between the laminar and turbulent flow regimes through the valve orifice) limited the valve performance capabilities. This work has proven this valve technology as a viable component within compact high performance hydraulic micropumping systems.

\section{ACKNOWLEDGMENT}

The authors are grateful to the following individuals who have supported this research work: K. Turner, for issues related to fillet radius control and eutectic bonding; J. Carretero and Dr. K. Breuer, for fluid flow modeling at the microscale; Dr. R. Mlcak, for fluid filling and sealing procedural development; Dr. Y.-H. Su, for nonlinear structural modeling contributions; and Dr. K.-S. Chen and Dr. L. Saggere, for additional structural modeling work. Additionally, the authors wish to acknowledge Dr. S.-H. Liou at the University of Nebraska for his generous support in the deposition of AuSn eutectic alloys and associated films on the piezoelectric materials used in this work.

\section{REFERENCES}

[1] H. Van Lintel, F. van de Pol, and A. Bouwstra, "Piezoelectric micropump based on micromachining of silicon," Sens. Actuators, vol. 15, pp. 153-167, 1988

[2] M. Stehr, S. Messner, H. Sandmaier, and R. Zengerle, "The VAMP-a new device for handling liquids or gases," Sens. Actuators, Phys. A, vol. 57, pp. 153-157, 1996.

[3] V. Gass, B. van der Schoot, S. Jeanneret, and N. de Rooij, "Integrated flow-regulated silicon micropump," Sensors and Actuators A, vol. 43, pp. 335-338, 1994.

[4] S. Shoji and M. Esashi, "Microflow devices and systems," J. Micromech. Microeng., vol. 4, pp. 157-171, 1994

[5] K. Ikuta, T. Hasewaga, and T. Adachi, "The optimized SMA micro pump chip applicable to liquids and gases," in Proceedings of the 2001 International Conference on Solid-State Sensors and Actuators (Transducers '01), 2001.

[6] M. Koch, N. Harris, R. Maas, A. Evans, N. White, and A Brunnschweiler, "Novel micropump design with thick-film piezoelectric actuation," Measure. Sci. Technol., vol. 8, no. 1, pp. 49-57, Jan. 1997.

[7] P. Watler and M. Sefton, "A piezoelectric driven controlled release micropump for insulin delivery," Trans. Amer. Soc. Artif. Intern. Organs, vol. XXXVI, pp. 70-77, 1990.

[8] B. Wagner, H. Quenzer, S. Hoerschelmann, T. Lisec, and M. Juerss, "Micromachined bistable valves for implantable drug delivery systems," in Proc. 18th Annu. Int. Conf. IEEE Engineering in Medicine and Biology Society, 1997, pp. 254-255.

[9] N. W. Hagood, D. C. Roberts, L. Saggere, K. S. Breuer, K.-S. Chen, J. A. Carretero, H. Q. Li, R. Mlcak, S. Pulitzer, M. A. Schmidt, S. M. Spearing, and Y.-H. Su, "Micro hydraulic transducer technology for actuation and power generation," in Proc. SPIE 7th Annu. Int. Symp. Smart Structures and Materials, vol. 3985, Newport Beach, CA, Mar. 5-9, 2000, pp. 680-688.
[10] H. Q. Li, D. C. Roberts, J. L. Steyn, K. T. Turner, J. A. Carretero, O Yaglioglu, Y.-H. Su, L. Saggere, N. W. Hagood, S. M. Spearing, M. A Schmidt, R. Mlcak, and K. S. Breuer, "A high frequency high flow rate piezoelectrically driven MEMS micropump," in Proc. IEEE Solid-State Sensor and Actuator Workshop, Hilton Head, SC, June 4-8, 2000, pp. 69-72.

[11] D. C. Roberts, J. L. Steyn, H. Q. Li, K. T. Turner, R. Mlcak, L. Saggere, S. M. Spearing, M. A. Schmidt, and N. W. Hagood, "A high-frequency, high-stiffness piezoelectric micro-actuator for hydraulic applications," in Proc. 11th Int. Conf. Solid-State Sensors and Actuators (Transducers '01), Munich, Germany, June 10-14, 2001, pp. 686-689.

[12] D. C. Roberts, N. W. Hagood, Y.-H. Su, H. Q. Li, and J. A. Carretero, "Design of a piezoelectrically-driven hydraulic amplification microvalve for high pressure, high frequency applications," in Proc. SPIE 7th Annu. Int. Symp. Smart Structures and Materials, vol. 3985, Newport Beach, CA, Mar. 5-9, 2000, pp. 616-628.

[13] D. C. Roberts, O. Yaglioglu, J. Carretero, Y.-H. Su, L. Saggere, and N. W. Hagood, "Modeling, design, and simulation of a piezoelectric microvalve for high pressure, high frequency applications," in Proc. SPIE 8th Annu. Int. Symp. Smart Structures and Materials, vol. 4327, Newport Beach, CA, Mar. 4-8, 2001, pp. 366-380.

[14] K. Henning, "Liquid and gas-liquid phase behavior in thermopneumatically actuated microvalves," Proc. SPIE-The Int. Soc. Optic. Eng., vol. 3515, pp. 53-63, 1998.

[15] C. Rich and K. Wise, "A thermopneumatically-actuated microvalve with improved thermal efficiency and integrated state sensing," in Proc. IEEE Solid-State Sensor and Actuator Workshop, Hilton Head, SC, 2000, pp. 234-237.

[16] H. Jerman, "Electrically-activated, micromachined diaphragm valves," in Proc. 1991 Int. Conf. Solid-State Sensors and Actuators (Transducers '91), 1991, pp. 1045-1048.

[17] M. A. Huff and W. L. Benard, "Thin film titanium-nickel shape memory alloy microfluidic devices," in Proc. Third Int. Symp. Microstructures and Microfabricated Systems, 1997, pp. 26-38.

[18] M. A. Huff, "Silicon Micromachined Wafer-Bonded Valves," Ph.D. dissertation, Massachusetts Institute of Technology, Cambridge, 1993

[19] M. Shikida, K. Sato, S. Tanaka, Y. Kawamura, and Y. Fujisaki, "Electrostatically driven gas valve with high conductance," J. Microelectromech. Syst., vol. 3, no. 2, pp. 76-80, June 1994.

[20] F. Pourahmadi, L. Christel, K. Petersen, J. Mallon, and J. Bryzek, "Variable-flow micro-valve structure fabricated with silicon fusion bonding," in Proc. IEEE Solid-State Sensor and Actuator Workshop, Hilton Head, SC, 1990, pp. 78-81.

[21] A. Meckes, J. Behrens, and W. Benecke, "Electromagnetically driven microvalve fabricated in silicon," in Proc. 1997 Int. Conf. on Solid-State Sensors and Actuators (Transducers '97), 1997, pp. 821-824.

[22] J. G. Smits, "Piezoelectric micropump with microvalves," in Proc Eighth Bienn Univ Gov Ind Microelectron Symp. (IEEE n 89CH2769-8), Piscataway, NJ, pp. 92-94.

[23] S. Kluge, G. Neumayer, U. Schaber, and M. Wackerle, "Pneumatic silicon microvalves with piezoelectric actuation," in Proc. 2001 Int. Conf. on Solid-State Sensors and Actuators (Transducers '01), 2001.

[24] M. Esashi, S. Shoji, and A. Nakano, "Normally closed microvalve and micropump fabricated on a silicon wafer," Sens. Actuators, vol. 20, pp. 163-169, 1989.

[25] M. Esashi, "Integrated micro flow control systems," Sens. Actuators, vol. A21-A23, pp. 161-167, 1990.

[26] S. Shoji, B. Van der Schoot, N. de Rooij, and M. Esashi, "Smallest dead volume microvalves for integrated chemical analyzing systems," in Proc. 1991 Int. Conf. Solid-State Sensors and Actuators (Transducers '91), 1991, pp. 1052-1055.

[27] J. Garcia-Bonito, M. J. Brennan, S. J. Elliot, A. David, and R. J. Pinnington, "A novel high-displacement piezoelectric actuator for active vibration control," Smart Mater. Struct., vol. 7, pp. 31-42, 1998.

[28] P. Tang, A. Palazzolo, A. Kascak, G. Montague, and W. Li, "Combined piezoelectric-hydraulic actuator based active vibration control for rotordynamic system," J. Vibration Acoust., vol. 117, pp. 285-293, 1995.

[29] W. Tsukamoto, "Piezo-actuator's displacement magnifying mechanism," U.S. Pat. 5233 834, 1993.

[30] Y. H. Su, K. S. Chen, D. C. Roberts, and S. M. Spearing, "Large deflection analysis of a pre-stressed annular plate with a rigid boss under axisymmetric loading," J. Micromech. Microeng., vol. 11, pp. 645-653, 2001.

[31] J. A. Carretero and K. S. Breuer, "Measurement and modeling of the flow characteristics of micro disk valves," in Proc. 1994 Int. Mechanical Engineering Congress and Exposition: Microfluidics Symposium, Orlando, FL, Nov. 2000. 
[32] K. S. Chen, A. A. Ayon, and S. M. Spearing, "Controlling and testing the fracture strength of silicon on the Mesoscale," J. Amer. Ceramic Soc., vol. 83 , no. 6 , pp. 1476-1484, 2000.

[33] K. T. Turner, "An evaluation of critical issues for microhydraulic transducers: silicon wafer bonding, strength of silicon on insulator membranes and gold-tin solder bonding," S. M. thesis, Massachusetts Institute of Technology, Cambridge, June 2001

[34] K. T. Turner, R. Mlcak, D. C. Roberts, and S. M. Spearing, "Bonding of bulk piezoelectric material to silicon using a gold-tin eutectic bond," in 2001 MRS Fall Meeting, Boston, MA.

[35] J. L. Steyn, H. Q. Li, D. C. Roberts, R. Mlcak, K. T. Turner, O. Yaglioglu, Y.-H. Su, M. A. Schmidt, S. M. Spearing, and N. W. Hagood, "Hydraulic amplification devices for microscale actuation," in Solid-State Sensor, Actuator and Microsystems Workshop, Hilton Head Island, SC, June 2-6, 2002

[36] S. E. Park and T. R. Shrout, "Characteristics of relaxor-based piezoelectric single crystals for ultrasonic transducers," IEEE Trans. Ultrason., Ferroelect., Freq. Contr., vol. 44, pp. 1140-1147, Sept. 1997.

[37] D. C. Roberts, "Design, modeling, fabrication, and testing of a piezoelectric microvalve for high pressure, high frequency hydraulic applications," Ph.D. dissertation, Massachusetts Institute of Technology, Cambridge, Feb. 2002.

[38] O. Yaglioglu, Y. H. Su, D. C. Roberts, J. Carretero, and N. W. Hagood, "Modeling, simulation and design of piezoelectric micro-hydraulic transducer devices," in Proc. Fifth Int. Conf. on Modeling and Simulation of Microsystems, San Juan, Puerto Rico, Apr. 21-25, 2002.

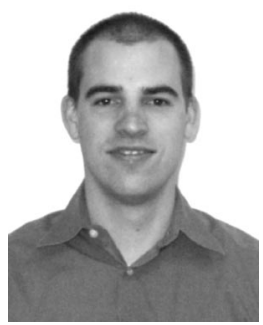

David C. Roberts received the S.B., S.M., and Ph.D. degrees in mechanical engineering from the Massachusetts Institute of Technology (MIT), Cambridge, in 1995, 1998, and 2002, respectively. His doctoral research in the Active Materials and Structures Laboratory at MIT was focused on the development of high-performance piezoelectrically driven microvalve and microactuator devices for hydraulic applications.

His research areas of interest include mechanical design and structural dynamics, as they relate to the development of microfabricated actuators and systems. He is employed as a mechanical engineer at Continuum Photonics, Inc., in Billerica, MA.

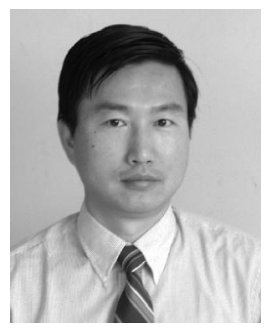

Hanqing $\mathbf{L i}$ received the B.S. degree in physics from Peking University, Beijing, China, in 1982 and the M.S. degree in material science at the General Research Institute for Non-ferrous Metals, Beijing, China, in 1985. He received the Ph.D. degree from the University of Nebraska-Lincoln, in 1998.

$\mathrm{He}$ was a Guest Scientist at NIST-Boulder, CO, from 1995 to 1998, a Postdoc at MIT between 1998-1999, and is currently a Research Scientist at Massachusetts Institute of Technology (MIT), Cambridge. His primary research interests are in MEMS fabrication and testing and superconducting devices.

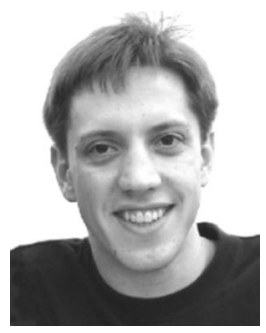

Lodewyk Steyn received the B.Eng. degree in mechanical engineering from the Department of Mechanical and Aeronautical Engineering, University of Pretoria, in 1998. He is currently pursuing a Doctoral degree in the Department of Aeronautics and Astronautics at the Massachusetts Institute of Technology (MIT), Cambridge. His research interests include the fabrication, packaging, instrumentation, and testing of piezoelectrically driven microfluidic devices for actuation and power generation applications.

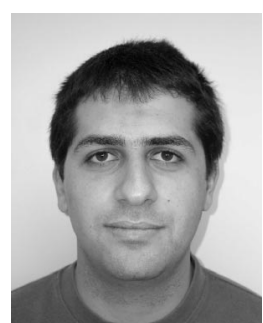

Onnik Yaglioglu received the S.B. degree in mechanical engineering from Bogazici University, Istanbul, in 1999 and the S.M. degree in mechanical engineering from the Massachusetts Institute of Technology (MIT), Cambridge, in 2002. His Master's research in the Active Materials and Structures Laboratory at MIT was focused on the modeling, simulation and design of piezoelectric microhydraulic transducer devices. He is currently working towards the Ph.D. degree in the Mechanical Engineering Department at MIT.

His research areas of interest include power MEMS, RF MEMS, power generation from ambient vibration, and microfluidics.

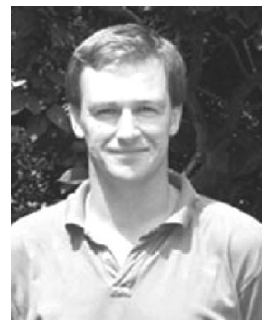

S. Mark Spearing received the Ph.D. degree from the Engineering Department at Cambridge University, U.K., in 1990.

From 1990 to 1992, he worked as a research engineer at University of California, Santa Barbara, where he produced analytical models for the failure of high-temperature ceramic materials and for Carborundum Microelectronics, where he was a member of the electronic packaging technology development team from 1992 to 1994 . He is an Associate Professor of Aeronautics and Astronautics at the Massachusetts Institute of Technology (MIT), Cambridge, where he has been since 1994. His technical interests include materials and structural analysis and design of MEMS, development of wafer bonding technologies, electronic packaging and advanced composites. Since 1995, he has been responsible for materials, structural design, and packaging tasks of the MIT MicroEngine, MicroRocket, Micro-chemical power, and MicroHydraulic transducer projects as well as conducting cross-cutting underpinning technology development.

Dr. Spearing is a Member of the ASME.

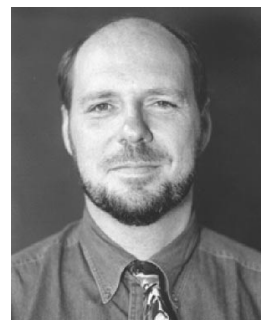

Martin A. Schmidt (S'88-M'88-SM'00) received the B.S.E.E. degree in electrical and computer engineering from Rensselaer Polytechnic Institute, Troy, NY, in 1981. He received the S.M. and Ph.D. degrees in electrical engineering and computer science from Massachusetts Institute of Technology (MIT), Cambridge, in 1983 and 1988, respectively.

In addition to his professorship in the Department of Electrical Engineering, he is the Director of the Microsystems Technology Laboratories at MIT. He investigates microfabrication technologies for integrated circuits, sensors, and actuators; design of micromechanical sensor and actuator systems; mechanical properties of microelectronic materials, with emphasis on silicon wafer bonding technology; integrated microsensors; and microfluidic devices. His current research projects involve novel applications of MEMS technologies to a variety of fields, including miniature gas turbines, miniature chemical reactors, microswitches, biological applications and sensors monolithically integrated with electronics.

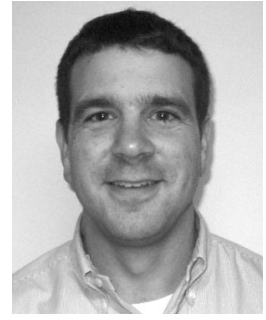

Nesbitt W. Hagood received the S.B., S.M., and Ph.D. degrees from the Department of Aeronautics and Astronautics from Massachusetts Institute of Technology (MIT), Cambridge, in 1985, 1988, and 1991, recpectively.

He is co-founder and currently Chief Technology Officer of Continuum Photonics, Inc. He was formerly a tenured Associate Professor of Aeronautics and Astronautics at MIT and Director of the Active Materials and Structures Laboratory. He specializes in the analysis, design and development of solid state actuation devices, microfabricated systems, and applications.

Dr. Hagood is an ONR Young Investigator and has received the Presidential Early Career Award in Science and Technology. 